\title{
Nicolás Maquiavelo (1467-1527): gobierno y política
}

Mercedes María Kerz ${ }^{1}$ CONICET - UP

\section{Artículo científico}

Material original autorizado para su primera publicación en el Journal de Ciencias Sociales, Revista Académica de la Facultad de Ciencias Sociales de la Universidad de Palermo.

\section{Recibido: 26-9-2016}

Aceptado: 13-1-2017

Resumen: En este trabajo se señala que los escritos de Maquiavelo, - fundamentalmente I/ principe y Discorsi sopra la prima deca di Tito Livio- constituyen obras fundamentales tanto para estudiar la relación que el florentino realiza entre política y gobierno como para analizar el espacio de acción político que dicha interacción produce.

La importancia de esta elección está en la afinidad del concepto gobierno con el núcleo central de la definición de la propia experiencia política. Para Maquiavelo, y esta es la tesis de estudio, la función del gobierno es dimensión propia de lo político; representa el elemento constante en su variada fenomenología. Además, es su compromiso con el conocimiento de las acciones de gobierno la prueba de una visión técnica y normativa sobre la política definida en términos de necesidad y ocasión.

Palabras claves: Maquiavelo, política, gobierno, dominio político.

\section{Niccolo Machiavelli (1467-1527): Government and Politics}

Abstract: The purpose of this paper is to show how Maquiavelli understands relationships between politics and government and how he analyzes the politics space built through these relationships. We encourage this objective, analyzing Il principe and Discorsi sopra la prima deca di Tito Livio as they are his most important books.

This option reflects the government affinity with the core concept of the definition of his own political experience. For Machiavelli, this role of government belongs to the dimension of political science; it represents the constant element in its varied phenomenology. In addition, his commitment with government actions is the proof of a practical and theoretical vision of politics in terms of need and context.

Keywords: Machiavelli, government, politics, political dominion.

\section{Nicolás Maquiavelo (1467-1527): gobierno y política}

\footnotetext{
${ }^{1}$ Licenciada en Ciencias Políticas. Profesora titular de Teoría Política, Universidad de Palermo. Correo electrónico: kerzmercedes@gmail.com
} 


\section{Introducción}

En una carta a Vettori ${ }^{2}$ del 9 de abril de 1513, Maquiavelo confiesa no saber hacer otra cosa que discurrir sobre el arte del estado. No duda en decir que, al impedirle la fortuna saber de lana, de ganancias o de pérdidas, sólo puede o bien razonar sobre el estado, o "hacer voto de silencio". Esto fue precisamente lo que no hizo; nos legó una obra que aún se piensa y que nos da pie para realizar nuestro estudio. A partir de la afinidad que para Maquiavelo hay entre política y acción de gobernar, nos proponemos elaborar un conjunto de proposiciones sobre esta articulación. El objetivo es analizar las relaciones de identidad significativa en cada uno de ellos, pero reconociendo a su vez que cada uno encuentra su dimensión constitutiva en el otro. La extensión de esta vinculación produce por sí misma la reflexividad de estos conceptos según la cual esta vinculación traspasa el umbral histórico de sus significaciones para llegar al teórico planteo de individualización por equivalencia entre política y gobierno; gobierno y política. Maquiavelo retiene la función identificadora de la actividad de gobernar como necesaria condición para pensar la especificidad de lo político.

Sin temor a ser redundante, las propuestas se inscriben bajo la idea de que le cabe a Maquiavelo la originalidad de haber detallado un conjunto de reflexiones que, aunque corrientes en su tiempo, no han perdido actualidad. Su compromiso con un camino aún no recorrido sobre asuntos que parecen beneficiosos a todos, prueba la existencia de su consciente responsabilidad con el discernimiento sobre política y gobierno. El recurso al conocimiento de la historia es el metódico camino escogido para entender con criterio de utilidad las acciones de los hombres en el ámbito de la ciudad que, en este caso, es sinónimo de república como dominio político territorial y no como forma de gobierno (Maquiavelo, 1987, Libro primero, proemio, pp. 25-27; 2, pp. 31-32).

Alejándonos de todo tipo de prohibiciones o descalificación que la persona y la producción de Maquiavelo produjeron, podemos sostener que sus escritos representan una influencia para todo aquel que lee y escribe sobre cuestiones políticas (Skinner, 1986; 1991; Puigdomènech, 1988; Borón, 2000; Hilb, 2000; Schettinno, 2002; Funes, 2004; 2014). Su actualidad está tanto en su capacidad de innovación como en el situar la vida real de los hombres como condición para toda reflexión política (Rinesi, 2005, 2014). En definitiva, podemos decir que su exigencia por observar en forma independiente y continua los asuntos del dominio político compone un universo de problemas donde generaciones de estudiosos ayudaron a gestar una concepción de política y de gobierno como forma permanente de razonamiento. En los inicios de la era científica, el florentino supo construir una teoría política que todavía tiene tantos tenaces defensores como agudos críticos, pero en unos y en otros ha dejado su huella.

Conocer las circunstancias en las que escribió Maquiavelo es el paso metodológico necesario para rescatar ideas en torno a la fecundidad de sus planteos sobre gobierno y política. Si el desafío es seguir pensando e

\footnotetext{
${ }^{2}$ Francesco Vettori (Florencia, 1474-1539). Fue historiador y político. Ejerció diversas misiones diplomáticas primero para el gobierno de la república y luego para los Médicis. Amigo personal de Maquiavelo, fue embajador frente al emperador Maximiliano y luego en Roma y en Francia. (Puigdomenéch, 1992, p. 47)
} 
interrogando a este pensador, entonces es indispensable situar su producción en su contexto, más allá (o precisamente por eso) de que sus planteos pasen a ser analizados desde lo que podríamos denominar un metafórico tiempo sin vencimiento. La idea de contexto a la que hacemos referencia comprende por una parte los escenarios políticos bajo los cuales los textos fueron escritos, los motivos por los cuales el autor los hizo, los resultados que buscaba producir y las convenciones que compartía con sus lectores a través de un cuerpo de conocimiento heredado y estabilizado; y por la otra, la trama intelectual dentro de la cual las redactó.

\section{Contexto}

Se sabe que Maquiavelo nació en Florencia el 3 de mayo de 1469 y que, si bien no existen muchos datos sobre su infancia y adolescencia, al asumir para sí la expresión de Tito Livio “Nací pobre y aprendí primero a pensar que a gozar" no es difícil comprender como vivió. En su familia no sobraba dinero y aunque su padre Bernardo trabajaba como abogado o aceptaba por necesidad trabajos donde el pago era en bienes, como fue el que realizó para el impresor Nicolo Della Magno para confeccionar un índice con los nombres que aparecen en Tito Livio, donde el pago fue un ejemplar, nunca descuidó la preparación de su hijo Nicolás en las disciplinas humanas. Esta denominación disciplinar, que derivaba siguiendo a Skinner (1991) de fuentes romanas, giraba en torno a determinados pilares: la valoración del conocimiento de la historia antigua, del latín, de la retórica, de la filosofía moral y de la imitación de los estilos clásicos (1991, pp.12-13). A partir del siglo XIV el humanismo se transforma en el alimento teórico indispensable para el ejercicio de la actividad política; en consecuencia, la acción de imitar se convierte en exigente copia de acciones virtuosas para el honor y la gloria de la res publica. Su formación humanista fue precisamente el motivo por el cual el gobierno de la República de Florencia lo eligió en 1498 para ser funcionario. En efecto, para desempeñar cargos de gobierno era requisito fundamental poseer fuertes aptitudes en materias humanísticas (latín, historia, filosofía antigua y retórica) además de saber redactar con claridad y precisión la correspondencia relativa a la administración del dominio político.

En cuanto a las circunstancias políticas que atravesaron el mundo de vida de Maquiavelo y que repercutieron en su capacidad de observación y reflexión, podemos rescatar el haber sido testigo tanto de importantes acontecimientos de la vida política de la ciudad de Florencia y de Italia, como de las de los principales países europeos. Este heterogéneo conjunto de acontecimientos comprende la tiranía civil de Lorenzo de Médici, la restauración y posterior fracaso de la república teocrática del dominico Jerónimo Savonarola (el profeta desarmado) ${ }^{3}$ (Colish, 1999, pp. 597-616), el gobierno republicano de Soderini (1494-1512) durante el cual Ileva adelante su actividad política más significativa, y finalmente la restauración en el poder de los Médici (1512-1520). Con relación a Europa, están los problemas de expansión y conquista territorial al mismo tiempo que los de las políticas de alianzas

\footnotetext{
${ }^{3}$ Cfr. Capítulo VI del Príncipe.
} 
de las grandes monarquías española, francesa y del imperio de los Habsburgo con respecto a principados, repúblicas, ducados, reinos o estados papales en Italia.

Maquiavelo es elegido el 19 de junio de 1498 Secretario de la Segunda Cancillería y posteriormente secretario de la Cancillería de los Diez. Así a las funciones relativas a los asuntos extranjeros le suma la de los asuntos internos y de guerra. Al momento de ser designado el panorama de la península itálica dista de ser tranquilo; no hay que olvidar que la temprana muerte de Lorenzo el Magnífico en 1492 fue el comienzo de un tiempo políticamente revuelto que conducirá a la casi totalidad de la península a quedar presa de las ambiciones geopolíticas de los estados y del imperio citado. Así a los habituales enemigos de Florencia dentro de la Toscana (Luca, Siena, Pisa, Pistoia) se agregan Venecia, el ducado de Milán, los Estados Pontificios y las ambiciones de César Borgia (hijo del Papa Alejandro VI) por constituir el Gran ducado de Romania con Bolonia como su capital.

No es inútil insistir que desde la entrada del rey de Francia Carlos VIII en 1494 para conquistar el reino de Nápoles y la similar acción de Fernando el Católico de España, además de las del Imperio, transformaron la geografía italiana en un tablero de ajedrez político donde los propios gobernantes italianos tenían poco que ofrecer para consolidar y defender sus territorios. Para completar la descripción de este contexto hay que indicar que cuando en 1512 se cierra la experiencia de la República y regresan los Medici al gobierno tras 18 años de ausencia ${ }^{4}$, los problemas internacionales no dejaron de acosar a la península y las guerras de predominio y hegemonías políticas territoriales continuaron.

El ejercicio de la función política de Maquiavelo más el contexto de acción fue conformando un conjunto de ideas dependientes de la experiencia que fue aprehendiendo, especialmente las enunciadas en torno a que las verdades políticas más importantes son las verdades de hechos, que el trabajo político es autónomo y diferente, y que el criterio de lo útil y necesario es el que prima por sobre cualquier otro. Dicho esto, podemos diferenciar en la vida de Maquiavelo dos grandes momentos. El primero corresponde a los años de su trabajo como diplomático y va desde 1498 a 1512. Durante esos años fue germinando su análisis sobre los procedimientos de los gobernantes, las formas de asegurar o no la continuada permanencia de una organización política, sea esta un principado (mixto, hereditario o

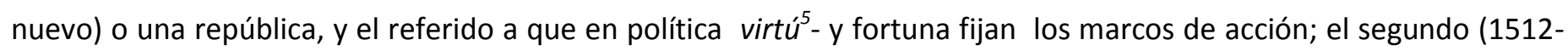
1527) al del escritor político y literario ${ }^{6}$ representando en este último aspecto y, como pocos, los deseos, angustias y contradicciones del Renacimiento italiano.

\footnotetext{
${ }^{4}$ Ante la posibilidad de ataque a Florencia de las tropas españolas dirigidas por el virrey de Nápoles Ramón de Cardona y acompañadas como legado pontificio por el Cardenal Medici, el Gonfaloniero perpetuo Soderini huye y así facilita un proceso de negociación que asegura la continuidad de la república. Con este fin se permite el ingreso de los Medici como simple ciudadanos y se comprometen a formar un gobierno de transición elegido entre los miembros del Gran Consejo por un periodo de catorce meses. Sin embargo, el 12 de septiembre de 1512 , los partidarios de los Medici ocupan la plaza de la Signoria y ponen fin al gobierno republicano.

${ }^{5}$ Según se desprende de los planteos de Maquiavelo, virtú es la capacidad y aptitud política del gobernante para la acción eficaz y efectiva. Asimismo, es expresión de virtud cívica sin fundamento teológico.

${ }^{6}$ En este estudio se prioriza al escritor político.
} 
Como consecuencia del retorno de los Medici, Maquiavelo, al verse privado de su cargo, del beneficio económico y condenado a vivir fuera de Florencia en la villa de Sant'Andrea en Percusina el Albergaccio (San Casciano en Val di Pesa), dedica buena parte de su tiempo a ordenar la experiencia adquirida, a interrogar a los clásicos y a bucear en el conocimiento histórico. Su objetivo es obtener un tipo de saber diferente de las recetas prescriptivas, predominante sobre gobierno y universo político. Dentro de estas coordenadas, hechos y pensamientos se imbrican de tal manera que el análisis de la actividad política conduce a su explicación y esta aporta entendimiento a la acción que en tanto tal es singular e inasible. Atento a lo dicho por Dante", no duda en afirmar que no se "llega a un verdadero conocimiento si no se asimila lo que se ha entendido" (2010, p. 323). Este es el sentido trasmitido en una carta de Maquiavelo a Francesco Vettori cuando, en pos de volver al trabajo político, sostiene que los "quince años que pasó estudiando el arte del estado, no los pasé ni durmiendo ni jugando: y todos deberían considerar el servirse de uno que, por haber servido a otros señores, está lleno de experiencia" (Nicolás Maquiavelo a Francisco Vettori 2010, p. 325).

Es a través de su intensa correspondencia, principalmente con Francesco Vettori, antiguo colega de legación y en ese momento embajador en la Curia romana, que conocemos cómo Maquiavelo sufre su exigido ocio, pero también cómo lo condujo a la producción intelectual. De un tiempo relativamente breve nacen sus grandes obras. El Príncipe, iniciado y terminado en 1513, después de suspender la redacción de los Discursos sobre la primera década de Tito Livio para finalizarlo en 1518.

Maquiavelo retornó a la Vita activa en 1520 al encargarle el estudio florentino del que está a cargo el cardenal Giulio de Medici una historia sobre Florencia. Así nace el Discorso sulle cose Fiorentina dopo la morte di Lorenzo, base para la redacción de lo que serán las Istorie fiorentine que presentará al cardenal, ya Papa Clemente VII en Roma en 1525. Además en 1521 ya se había editado el Arte della Guerra. Historia florentina no es un libro menor; pues tiene en sí toda una situación extremadamente compleja y un contenido que ha llamado la atención de Montesquieu (1869 1755), Rousseau (1712 - 1778) o, entre otros, Benjamín Constant (1767 - 1830). No hay que dejar a un lado la situación de que el texto fue encomendado por un adversario de aquellos que ocho años antes lo habían excluido de la política activa y prohibido su ingreso al Palazzo Vecchio. Así, las preguntas en torno a si traicionar sus ideales republicanos o a sus análisis sobre el ejercicio del poder regio en tiempos de excepción, o si debía aprovechar el caprichoso beneficio que la fortuna le concedía para enseñar al poderoso la disciplina de la virtú fueron, posiblemente, las que fuertemente lo provocaron en el momento de su aceptación ${ }^{8}$.

A su vez, al preocuparle a Florencia las consecuencias que para la ciudad podrían tener las siempre renovadas guerras franco-habsbúrgicas, crea la nueva magistratura de los Cinco Procuradores de los muros, nombrando como secretario a Maquiavelo con la tarea de controlar las fortificaciones de la ciudad. Llega el momento de poner en

\footnotetext{
${ }^{7}$ Carta de Maquiavelo a Francesco Vettori del 10 de diciembre de 1513

${ }^{8}$ Las respuestas a estos interrogantes discrepan. Cfr : Strauss, 1964; 2009; Sasso, 1993; Mansfield, 1996)
} 
práctica aquello sobre lo que había reflexionado teórica y prácticamente: es decir, acerca de un sistema militar ciertamente útil. Sus inquietudes no fueron exageradas; no hay que olvidar que en 1527 Carlos de Borbón asedia los Estados Pontificios y, finalmente, aplicando una política de escarmiento al papa Clemente VII por su inclinación profrancesa, autoriza el saqueo de Roma. En aquel lugar, los lansquenetes imperiales, que desde hacía meses no recibían paga, se dedican al saqueo de la ciudad y una guarnición del emperador, formada en su mayoría por soldados influidos por las ideas protestantes de Martín Lutero, hace prisionero al papa.

El fin del papado de Clemente VII no solo significó la segunda caída de los Medici sino la restitución de la República. A Maquiavelo le llega la noticia en Civitavecchia y rápidamente regresa a Florencia. Sin embargo, no es bien recibido. Su colaboración con el gobierno destituido generó desconfianza sobre su futuro compromiso y adhesión, sumada a las originadas por su independencia de criterios al estar sus escritos fuera de las corrientes predominantes. Para ese entonces comenzaban a escucharse las primeras críticas al Príncipe. Por último, el nuevo gobierno nombraba como secretario a un ex funcionario de los Medici. Maquiavelo enfermó poco tiempo después de la elección de Tarugi, y murió el 21 de junio de ese mismo año.

Lo hasta aquí desarrollado nos permite ver cómo los escenarios políticos y la trama intelectual de la época de Maquiavelo constituyen la plataforma de los textos que siguen tan presentes en nuestros días. Más allá de esto o precisamente por esto, la utilidad de este apartado se resume en que nos autoriza a presentar en el capítulo siguiente las proposiciones acerca de la vinculación entre gobierno y política a través de su visión técnica y normativa de la política donde, como se sostuvo en la introducción, sus ángulos de giro son las categorías de ocasión-necesidad cual virtù y fortuna. Además, este apartado nos permitió conocer, por una parte, cómo Maquiavelo a través de su espacio de experiencia temporal fue dando sentido a los acontecimientos y, por la otra, cómo insertó horizontes de expectativas en ese mismo espacio. Por último, y anticipando el apartado siguiente, sus libros El Príncipe y los Discursos son las pruebas más acabadas de esta conjunción y el punto de inicio de su conversión en un autor clásico.

\section{Proposiciones}

El cometido de este capítulo es entonces presentar algunas proposiciones sobre aspectos decisivos de la vinculación entre acción de gobernar y política, destacando los centrales atributos que las categorías virtú y fortuna tienen en nuestro autor. Pero este objetivo presume un punto de partida: dado que el trabajo se apoya en la lectura de las obras citadas de Maquiavelo, corresponde presentar algunas ideas en torno al Príncipe y los Discursos.

A la pregunta ¿qué decir del Príncipe? podemos responder que es un libro breve, conciso, incisivo y escrito con lucidez; es un intento por entender y reaccionar ante la realidad de la península itálica del siglo XV y principios del XVI y por proveer una teoría política práctica y reglas de gobierno que cualquier jefe de Estado de cualquier tiempo tiene que conocer para obtener, asegurar, consolidar y conservar el poder y el dominio político (Kerz-Prieto, 2008). Es 
también un tratado en el que se reflexiona sobre un campo de acción específicamente político, diferente y autónomo del surgido de las prescripciones de la moral cristiana y, finalmente un "breviario político" que presenta no sólo una idea de verdad política opuesta a la verdad universal sino también la referida a que es en el antagonismo entre política y moral donde se ubica la cuestión relativa al quién y cómo del gobierno, e incluso la propia ética de la actividad política.

Desde estas caracterizaciones podemos decir que la escritura en forma de dilema ${ }^{9}$ que Maquiavelo adopta en esta obra es instrumentalmente intencional; sólo así puede observar y explicar los acontecimientos y, simultáneamente, aconsejar al gobernante un hacer político que subordine, o más precisamente se independice de la moral en el momento de la adopción y puesta en práctica de la decisión política. Maquiavelo se aleja entonces de las respuestas formuladas por la tradición para rastrear en las huellas de la experiencia política lo específico de la condición política.

Los Discursos sobre la primera década de Tito Livio son igualmente claros y definidos. Y a diferencia de lo que algunos exégetas han sostenido, no significan un corte radical con respecto al Príncipe, sino que, por el contrario, podemos pensar que los temas tratados en este breve libro se insertan en la estructura de los Discursos. Las disquisiciones maquiavelianas acerca de la actividad política, de los problemas de constitución y ordenamientos de los distintos dominios políticos, de las vinculaciones entre imperium, poder y seguridad, y los derivados del pesimismo antropológico como causa de justificación de las decisiones de los hombres políticos, se mantienen. Cambia, eso sí, el foco de interés del autor; en esta obra el análisis se centra en estudiar el fenómeno de la república. Podríamos incluso decir que Maquiavelo utiliza el concepto bajo una doble significación: un sentido amplio y uno restrictivo. Bajo el primero, con república alude a la organización territorial de la cosa pública, independientemente de los tipos y modalidades bajo los cuales se organiza ${ }^{10}$. En el libro primero de los discursos se puede leer lo siguiente: "Porque en todas las repúblicas, de cualquier modo que estén organizadas, sólo cuarenta o cincuenta ciudadanos ocupan los puestos de mando [...]" (Discursos, I; 16, p.80). Con el segundo, en cambio, se refiere a específicas formas y modalidades que adopta la organización político territorial. En este sentido, plantea que la república es una singular forma de gobierno basada en la organización libre de la vida ciudadana y en el imperio de la ley. Esta organización, según su escrito, es propia de "pueblos en los que la corrupción no se ha desarrollado todavía, y donde se encuentra más de lo bueno que de lo malo" (Discursos, I, 16, pp. 77-78).

- De acuerdo con estas escuetas presentaciones y en lo que respecta a la lectura de estos textos, argumentamos que el común denominador de sus análisis está en la idea acerca de que la realidad política es producto y productora de fuerzas antagónicas y que es el conflicto entre ocasión y necesidad - fortuna y virtú- el que define su espacio y tiempo de acción. Este

\footnotetext{
${ }^{9}$ En términos generales, Maquiavelo presenta en sus obras una estructura dilemática de análisis; es decir, escribe sus argumentos sobre dos proposiciones contrarias disyuntivamente, de tal manera que, negada o concedida cualquiera de las dos, demuestra una conclusión.

${ }^{10}$ Idea presentada en el inicio de este escrito.
} 
argumento es central en esos libros; está presente en las cuestiones de las que se ocupa y, particularmente en el tema objeto de este estudio: es decir el de la vinculación entre acción de gobernar y política.

- $\quad$ Por último, no constituye un dato menor la presencia de reflexiones de orden prescriptivas. Maquiavelo no aspira a un planteo carente de consecuencias. Sabe que el modo de ver los fenómenos expresados en sus obras depende del lugar en que se sitúa como observador, y ese lugar no está exento de un cierto tipo de valoraciones que le pueden ocasionar dificultades y sinsabores. Los valores que defiende Maquiavelo, si bien no son los que conforman la ética cristiana, no por ello dejan de tener influencia en su pensamiento. Hay todo un vocabulario en su obra que lo indica, aunque no guíen la orientación de su análisis. Podemos arriesgar la idea en torno a la existencia de lo que podemos denominar una ética de la necesidad política, en la que virtú y fortuna se entrelazan fuertemente, pero sin eliminarse una a otra. Los valores a los que esta ética hace referencia (crueldad, engaño, fuerza, astucia, incumplimiento de las promesas, por ejemplo) son los que precisamente se transforman en horizonte de expectativa en los planteos de sus textos. No está demás decir que el florentino no se inscribe ni defiende ningún planteo teórico que refiera a la amoralidad de las acciones, e incluso en ocasiones su terminología y en parte su sentido se inserta dentro de las convenciones humanistas predominantes: príncipe sabio, príncipe virtuoso, príncipe prudente, buen gobierno, entre otras, forman parte de la tradición del discurso propio del Humanismo renacentista italiano. Más aún, cuando en los Discursos aparece la muy usada expresión de la época "medicine forti" (Discursos, I 8 y 17) para referirse al uso, por ejemplo, de la crueldad en la actividad política, es consciente y expresa claramente que es la realidad la que la impone y no la ponderación de su valor. Además, no duda en escribir en El Príncipe que su uso podrá estabilizar al gobierno, pero no dará gloria (virtud política por excelencia) a su gobernante. Se puede argumentar que la continua crítica que Maquiavelo hace a los políticos de su tiempo se realiza sobre la base del no reconocimiento en ellos de todo sentido de gloria cuando es esta la mayor recompensa propia en este mundo. Asimismo, su interés por cómo mutan, varían y se alteran los Gobiernos no se aleja demasiado del mostrado por la teoría política del temprano renacimiento italiano. Desde esta perspectiva, Maquiavelo considera estos problemas como corolario de su preocupación por lo que permanece y perdura.

Llegado a este punto nos interesa presentar las proposiciones relativas a la vinculación que este autor realiza entre acción de gobernar y política. La idea planteada en la Introducción acerca de la función identificadora de la actividad de gobernar como condición necesaria para 
pensar la especificidad de la política guía la elaboración de las tres tesis que se formulan. A la vez, es útil para escribir el argumento central de las proposiciones bajo las siguientes ideas: es posible encontrar en los planteos de Maquiavelo específicas referencias a los elementos que conforman la acción de gobernar como actividad de guiar, organizar y conducir a hombres que habitan en una organización política; de ahí que para el florentino no hay ámbito específicamente político sino que se considera a la acción de gobernar como inherentemente constitutiva de su dimensión vertical.

- $\quad$ Primera Proposición.

- La persuasión y la fuerza son los recursos indispensables para la acción de gobernar. La seguridad y continuidad del dominio político territorial como fin político en sí avalan el empleo de estos medios y evidencian la dimensión vertical de la política.

Este enunciado proposicional expresa que para Maquiavelo la elección de los fines y el cumplimiento a los objetivos fijados por el gobernante se vuelve cara visible de la supremacía del gobierno en el universo político. Además, es esta misma capacidad la que hace del gobernante la figura imprescindible para ordenar a los hombres que habitan ese dominio de manera segura y tranquila.

- $\quad$ Al mismo tiempo, Maquiavelo no ignora que su análisis tiene que expresar del modo más preciso significados y definiciones, y en este caso la noción de una relación entre gobernante y gobernados es observada como constante; su presupuesto es el reconocimiento de una permanente situación de conflicto e inseguridad, ya que los hombres sólo obran bien por necesidad, pero al ser por naturaleza malos, ponen en práctica acciones "perversas" que, según lo merite la ocasión, confrontan con el gobierno. Son los hombres los que en sus acciones respetan o violentan la acción del gobernante, determinando, en consecuencia, que el gobernante se valga de los medios políticamente adecuados para obtener éxito o, al menos, evitar su fracaso.

- De lo que está seguro Maquiavelo es que ningún príncipe nuevo puede optar por "el camino del medio" porque al no saber ser ni del todo bueno, ni del todo malo, no mantiene su gobierno ni el principado; hay ocasiones que por su naturaleza exigen procedimientos crueles que, si bien son "enemigos de toda vida no solamente cristiana, sino humana, y cualquier hombre debe evitar emplearlos [...]" (Discursos, Libro 1, 26, p. 99) ayudan a que el principado nuevo continúe. 
- $\quad$ Está claro que el argumento admite que los medios para el logro de esa prioridad son el uso de la persuasión. En los Discursos plantea incluso lo importante que es el hablar por parte de un príncipe bueno para el control de los tumultos (Libro 258 , p. 171) y la fuerza; aunque las más de las veces, y según el tipo de organización del dominio político y comportamientos de las facciones y de la multitud, el platillo de la balanza se incline por el uso de la fuerza física sobre la persuasión, siempre el gobernante debe "aparentar" evitar mostrarse enemigo de sus propias leyes. Para dar cuenta de este "aparentar" de una acción virtuosa, Maquiavelo pone como ejemplo al papa Alejandro VI porque:

No hubo jamás hombre alguno que aseverara con mayor eficacia ni que afirmara cosa alguna con más juramentos y que, sin embargo, menos la observara: y a pesar de ello siempre le salieron los engaños según sus deseos, porque conocía bien este aspecto del mundo (EI Príncipe; cap. XVIII, p. 140).

- Lo que definitivamente entra en juego en este planteo es el deber del gobernante de conservar y dar estabilidad a la organización política de su gobierno en pos de la duración del dominio político territorial. De ahí que, y además de lo dicho, la necesidad de este cumplimiento sea la guía que orienta, por ejemplo, el respetar o no la palabra comprometida. Saber reconocer la ocasión para esta necesidad es el parámetro que encuadra la acción del gobernante porque y, según se ha dicho, en el caso de los principados nuevos, le corresponde al gobernante -príncipe- procurar ganar y conservar el estado y, en este caso "los medios serán juzgados honorables y alabados por todos; ya que el vulgo se deja cautivar por la apariencia y el éxito, y en el mundo no hay más que vulgo" (El príncipe, cap. XVIII, p. 141). Además de utilizar las acciones de Alejandro VI para probar sus argumentos, Maquiavelo, a continuación del texto citado refiere, sin nombrarlo, las realizadas por el rey de España Fernando el Católico, sosteniendo que "no predica más que paz y lealtad cuando de la una y de la otra es acérrimo enemigo; y tanto la una como la otra, de haberlas observado, le habrían arrebatado o la reputación o el estado" (El príncipe, cap. XVIII, 141).

Al llegar a este punto resulta necesario retomar el fin de la cita referida a que el vulgo se deja cautivar por la apariencia y el éxito, para hacer hincapié en la idea que el florentino tiene con respecto a este; o sea, a ese "hombre común" que no gobierna ni tiene, al menos en la generalidad de los casos, deseo ni ambición de hacerlo. Entendemos que este aspecto contribuye a resaltar la comprensión de la dimensión vertical de la política. Los gobernados se diferencian de los gobernantes por sus actitudes de distancia o acercamiento; prima la primera si el gobernante les 
garantiza seguridad y libertad en sus asuntos privados, o la segunda cuando ansían obtener ganancias sobre el ofrecimiento y peligros remotos o, como lo plantea en la Historia de Florencia y siguiendo el ejemplo de Tucídides y Livio, cuando le hace decir a un anónimo protagonista de las revuelta de los Ciompi que se deben buscar dos fines: a) no ser castigados por lo hecho el día anterior, y b) poder vivir más libremente y de una forma más satisfecha que en el pasado (2009, III, p. 701).

Es la antropología negativa de Maquiavelo la que contribuye a afirmar la política en su vértice. La ingratitud, hipocresía, cobardía y demás defectos del hombre funcionan a la manera de ley histórica natural como fundamentos del mando y de sus acciones. Por supuesto que según el tipo histórico de organización habrá matices en el tratamiento de Maquiavelo sobre este colectivo. Si en los Discursos aparece potenciada la virtud del pueblo por el despersonalizado predominio de los ordenamientos legales, de la educación y de la religión y en El príncipe la virtú regia del mando, el dato común para explicar cómo varían y cambian las organizaciones políticas lo constituye tanto la búsqueda constante de seguridad, poder y riqueza como el egoísmo y la primacía de interés particular, la corrupción y el "que la fe y benevolencia de los hombres no es duradera" (Discursos, II, 10, pp. 208-209); al ser mayor el número de los gobernados por sobre quién gobierna, son los que en definitiva terminan confirmando la verticalidad de la política (Sartori, 1987). De esta realidad surge la inevitable necesidad del gobernarte de establecer el orden político porque, como escribe Maquiavelo invocando a Virgilio, una multitud es inútil sin cabeza (Discursos I, 23 p. 137).

En definitiva y como síntesis de la proposición planteada, Maquiavelo dirige su atención a un problema que pasará a formar parte del núcleo duro de la reflexión politológica, nos referimos a lo que escribió como consecuencia de lo que hizo como funcionario de la república en torno al fenómeno gobierno. Sus interrogantes acerca de quién gobierna, cómo, cuándo, por qué, dónde y con qué efectos son medulares al momento de sistematizar en forma escrita aquello que ha hecho, observado y aconsejado durante el ejercicio de sus funciones políticas. El observador científico observa a los sujetos que se encuentran actuando en la realidad en cuestión, procurando entender el gobierno desde el ámbito autónomo y diferente de la política ${ }^{11}$. Es decir, se ocupa de deducirlo desde la visión de ser un fenómeno independiente respecto de los distintos grupos sociales, que tiene la específica tarea de llevar a cabo la integración de la sociedad y defenderla de los grupos externos.

-

Segunda Proposición.

- $\quad$ El único criterio para distinguir el buen gobierno del malo es el éxito en el cumplimiento de los fines perseguidos. Los indicadores efectividad y eficacia, sin ser las únicas, son dimensiones constitutivas del fenómeno gobierno ya que apuntan al conjunto de capacidades y habilidades

\footnotetext{
${ }^{11}$ Hay que destacar que Maquiavelo para referirse a los problemas y actividades calificadas como políticas usa más el vocablo latino imperium que políticus (Rubinstein, 1987; Viroli, 1992).
} 
que tienen que tener los sujetos de la acción y/o los ordenamientos políticos para alcanzar resultados.

- $\quad$ Para introducirnos en el desarrollo de los argumentos que validan esta proposición, hay que aclarar los conceptos de efectividad y eficacia. Entendemos por efectividad al entramado de capacidades y habilidades para poner en práctica medidas que permitan alcanzar fines estipulados de antemano. El grado de aceptación de los fines logrados es directamente proporcional al compromiso inicial de los destinatarios con los ejecutores y decisores. El concepto, si bien pone su atención en la relación entre medios y fines, define su sentido por los resultados. Los fines calculados de antemano se convierten en orientadores de los medios a emplear. Por eficacia se entiende la capacidad de los ordenamientos o, mejor dicho, de las estructuras para escoger y ejecutar decisiones indispensables, ya sean para superar los retos planteados al gobierno o para alcanzar los diversos fines queridos por los gobernados ${ }^{12}$. La primera parte de esta definición es auto-referencial ya que apunta a las capacidades institucionales para consolidar el funcionamiento del ordenamiento político del que se trate mientras que la segunda se dirige a evitar por previsión o reacción situaciones no gobernables.

Para Maquiavelo entonces el gobierno implica una actividad orientada hacia un fin, para lo cual el gobernante debe poseer en forma efectiva y eficaz las capacidades políticas suficientes para controlar, maniobrar y estabilizar los ordenamientos que dan forma al cuerpo político. De tal forma, el gobierno pasa a ser una especie de recipiente dentro del cual se coordina el ejercicio del poder y la estructura institucional que lo sostiene. En términos de efectividad, pero también de eficacia, el florentino no elude plantear la relación entre fuerza y gobierno; deja a la fuerza el lugar de medio necesario y extremo para evitar situaciones no gobernables (licenza) que, para su forma de pensar, constituye el sinsentido de la política porque pone en evidencia la "ausencia de todo gobierno e institución" (Funes, 2004, p.19) y, en consecuencia, toda imposibilidad de coexistencia social. Maquiavelo no duda en sostener que, después de la expulsión de Piero de Lorenzo de Medici de Florencia en 1494, el gobierno desapareció dejando en su lugar un desorden tan generalizado que liberó todas las ambiciones, de modo que las cosas públicas fueron de mal en peor (Discursos, $1 ; 46$, p.144).

Con cierta indiferencia normativa con respecto a las modalidades de adquisición, utilización, concentración y distribución del poder, Maquiavelo ve la necesidad de su centralización como barrera de contención frente a las situaciones de crisis que, por lo demás y, particularmente en Italia, son habituales y recurrentes. Son estas situaciones

\footnotetext{
${ }^{12}$ Para definir estos conceptos se consideraron las definiciones aportadas por Linz en su obra La quiebra de las democracias (1991:43) y por la de Morlino Como cambian los regímenes políticos (1985, p.219).
} 
las que provocan su respuesta en favor de aquella concentración y las que influyen en la demostración de un estado de angustia recurrente ante la pregunta por el futuro histórico inmediato. En orden a su método pragmático de análisis, donde la desapasionada observación se ubicaba en el centro de su pretensión de conocimiento, Maquiavelo recurre a la historia como una especie de inacabado lugar de experimentación de acciones y comportamientos de los hombres para encontrar, en el sentido griego de la palabra, fuentes de "imitación” para conocer y practicar el arte de gobernar. No duda en observar que el conocimiento de la historia ayuda a extraer su sentido y gozar del sabor que encierra (Discursos, I proemio, p. 26). Además, imitar el caminar que otros hicieron es regla general para afirmar principados, repúblicas y a sus gobiernos como soporte real. En el libro VI del Príncipe no duda en afirmar que el hombre prudente:

debe seguir los caminos recorridos antes por los grandes hombres; e imitar a aquellos que han sobresalido de manera extraordinaria sobre los demás, para que aun cuando su virtud no alcance la de estos, se impregne, al menos un poco, en ella. (El príncipe, cap. VI, p. 90)

La república romana le enseña al príncipe que además de la necesidad de ser un hombre excepcional y virtuoso, tiene que disponer de leyes adecuadas y lograr que un pueblo no se corrompa. Ahora bien, las leyes son insuficientes si no están acompañadas por el poder de las armas, o sea, por la posibilidad cierta de la coacción física. El gobierno que logra articular la fuerza de la ley con el poder de las armas se afirma en su continuidad y aceptación por parte de aquel "universal". Para Maquiavelo, la interdependencia que existe entre estos factores no sólo es un hecho observable, sino que es recomendable para el éxito del buen gobierno. En sus consejos al gobernante recomienda el uso de la fuerza violenta ante la posibilidad cierta de que sus mandatos no sean cumplidos por súbditos y aliados, y el respeto a la ley o, al menos, el aparentar hacerlo porque son las leyes las que hacen buenos a los hombres (Discurso I, 3, p. 38). El recurso al "reprochable método" del uso de la violencia física está limitado a su ejercicio virtuoso que, como ya se ha dicho, no tiene que ver con un comportamiento anclado en el deber ser del buen gobernante, sino en la virtú política que, en este caso se exterioriza cuando el gobernante, en pos del efecto buscado, sabe reconocer el momento adecuado para utilizarla en forma decidida y sin dilación (El Príncipe. cap. III, pp. 79-83).

Un gobierno es efectivo, siguiendo la argumentación de Maquiavelo, si desde antemano fija como principal finalidad de su gobierno el poder de mando de la autoridad, la consolidación del dominio político y el éxito en la obediencia de sus gobernados; y eficaz cuando a través del reconocimiento y la satisfacción de las demandas de los gobernados logra aumentar los apoyos de la multitud y neutralizar los humores sociales. La ineficacia como contracara fomenta el odio de los súbditos, y esto es peligroso porque estimula el deseo de venganza, de rebelión y de envidia; pasiones todas que si el príncipe no las sabe contener se transforman en fuentes de conspiraciones con el consabido peligro que ello significa para el dominio territorial que preside y para la continuidad de su gobierno. 
En definitiva, un gobierno es eficaz y eficiente cuando logra que sus decisiones sustraídas a la capacidad de los individuos alcanzan, por un lado, un adecuado cálculo de continuidad gracias a la obtención de resultados exitosos con respecto a los fines y, por el otro, un afinado vínculo de obligación; es decir, cuando el gobierno logra que la colectividad acepte medidas y decisiones que, si bien no han sido decididas por ella, son reconocidas por el conjunto como beneficiosas. Conforme a lo ya dicho en la preposición anterior, la razón estriba en que el interés del mayor número de los gobernados no es alcanzar el poder, sino vivir en seguridad y con libertad sabiendo que, con respecto a esta última, siempre existe una minoría que quiere ser libre para mandar y, por lo tanto, sus conformidades con los fines perseguidos y las acciones empleadas por el gobierno serán otras (Discursos, I, 16, p. 80). El gobernante es eficaz, sabio y prudente en la terminología de Maquiavelo, y el gobierno, efectivo, cuando tiene la capacidad/ habilidad de reconocer los males antes de que aparezcan. En caso contrario, será tenido por cruel o débil y el gobierno como inoperante. El prever para prevenir (vedere discosto) es la característica predominante de un gobierno efectivo y eficaz porque puede poner remedios cuando tempranamente ve nacer los conflictos. Si lo hace, los gobernados están contentos porque saben que pueden recurrir al príncipe, con lo que "tienen más motivos para amarlo, si quieren ser buenos y de temerlo, si quieren ser de otra manera" (El príncipe, cap. III, p.77).

Entendemos que estas argumentaciones forman parte de la razón principal del florentino para observar que, si un gobernante no está dispuesto a hacer algunas cosas malas, hará peor porque con su descuido arruinará a todos. Y si esta es una noción acerca de que el fin justifica los medios, no es cualquier fin sino sólo el que tiende al bien del dominio político y, por ende, de sus gobernados. Efectividad y eficacia, más que conjugarse, deben converger como indicador de éxito del gobierno.

No está de más volver a sostener que no es lo bueno ni lo moral el fundamento del planteo maquiaveliano, sino lo útil y necesario. Maquiavelo abandona los fundamentos del sistema político medieval. Deja de lado, incluso por parecerle fantástico, el fundamento del origen divino de los reyes, para plantear en el capítulo XV del Príncipe los comportamientos que un gobernante debe tener tanto para los súbditos como para los amigos. Confiere autonomía y especificidad a la política, y con ello al gobierno, porque su finalidad es escribir desde el umbral de la verdad efectiva cosas útiles para el gobernante.

Para concluir con los argumentos referidos a esta segunda proposición podemos sostener que Maquiavelo diferencia con claridad el buen del mal gobernante y, de esta manera, el buen gobierno del malo; para ello, fija su juicio en la condición de efectividad y eficacia política. El "minotauro" de esta concepción es descripto por él con claridad cuando, en su recomendación al gobernante (príncipe en su léxico), le indica que debe saber comportarse como bestia y como hombre, y que es la ocasión la materia sobre la que se plasma el comportamiento escogido, aunque todo gobernante debe saber con antelación que ninguno de los dos se mantiene por sí solo (El príncipe cap. XVIII, pp. 138-139). Podemos argumentar que el lema observar lo observado por otros es la metodológica condición 
para el éxito de este minotauro político (El príncipe, cap. III, p. 84). Un buen gobierno, por lo tanto, es el resultado de la cohabitación de príncipes seguros con seguros ciudadanos (Discursos, I, 10, p. 62) y su funcionamiento está en relación con las capacidades de efectividad y eficacia decisorias.

\begin{abstract}
Tercera Proposición
Disponer de la fuerza no es sinónimo de autoridad. Autoridad es el poder que gobierna o ejerce el mando, da órdenes y hace respetar leyes y ordenamientos. Gobernar implica organización de bienes y riquezas y la puesta en práctica y seguimiento de las órdenes emanadas de la autoridad por un conjunto de "funcionarios" elegidos sobre la base de esa misma finalidad. La obligación funcional de este "entorno" se vincula con las tres responsabilidades básicas asociadas a la función de gobierno. Una correspondiente a la protección de la comunidad política frente al exterior, la segunda a la pervivencia de la misma autoridad, y la última al mantenimiento de esa unidad política hacia el interior.
\end{abstract}

No hay en Maquiavelo una teoría de la autoridad que sólo vea en esta una expresión de la fuerza y, por más que no la descarta, como ya se ha expuesto repetidamente, no reduce su concepto de autoridad a su uso; incluso es posible encontrar en sus escritos consideraciones acerca de que la primacía de la fuerza niega la existencia de la primera. El poder de la autoridad puede y debe según las ocasiones emplear la fuerza; es la autoridad la que la engendra, pero no la fuerza su fundamento. Conforme a esta conceptualización, puede leerse en el capítulo XIV de EI príncipe lo siguiente:

Un príncipe, pues, no debe tener otro objetivo, ni otra preocupación, ni considerar cosa alguna como responsabilidad personal, excepto la guerra y su organización y reglamentación, porque éste es un arte que compete exclusivamente a quien manda; y comporta tanta virtud que no sólo mantiene en su lugar a quienes han nacido príncipes, sino que muchas veces eleva a este rango a simples ciudadanos. (El príncipe cap. XIV, p.126)

Luego, agrega en el capítulo XVIII que el príncipe tiene dos modos de combatir "uno con las leyes; el otro con la fuerza; el primero es propio de los hombres, el segundo de las bestias; pero, puesto que el primero muchas veces no basta, conviene recurrir al segundo" (EI príncipe cap. XVIII, p. 138). Por último, en los Discursos justifica que la autoridad use la violencia tan sólo si contribuye a la creación de la paz y el orden, en beneficio del pueblo, es decir de muchos contra pocos $(1,9)$.

La autoridad como agente y poder que gobierna es activa, consciente y es la que hace cambiar los comportamientos de los otros. Para nuestro autor, la acción autoritaria se distingue por una especie de inherente contradicción porque, mientras por una parte implica la posibilidad del gobernante de actuar sobre los demás impidiendo que reaccionen, por la otra presupone -por esta misma condición- la posibilidad de la oposición y, en consecuencia, la de destrucción de la autoridad. Un paradigmático ejemplo de la dialéctica entre reconocimiento y negación de la autoridad lo constituye la observación de Maquiavelo acerca de las dificultades que tiene una autoridad nueva para hacer reconocer y que sea aceptado su nuevo ordenamiento político. Analiza el florentino la 
posibilidad real de la oposición porque "todo innovador tiene como enemigo a cuantos el viejo orden benefició y como tibios defensores a aquellos a los que las nuevas leyes beneficiarían" (El príncipe, cap. VI, p. 92). Además, la experiencia le confirma que los hombres son incrédulos y no confían en las novedades hasta no afirmarse; de ahí que la enemistad se manifiesta cada vez que se cuestiona la autoridad y se la combate, escribirá en ese mismo capítulo y en esa misma página, con "pasión facciosa". Estas son las razones que están presentes cuando Maquiavelo define por única vez en forma taxativa qué significa gobernar. En los Discursos lo define como la acción que la autoridad lleva adelante con el fin de "mantener a los súbditos de modo que ni deban ni puedan perjudicarte", agregando que esto "se consigue o con grandes medidas de seguridad, cortándoles toda posibilidad de ofenderte, o con beneficios, de modo que no sea razonable que puedan desear cambiar de suerte" (II, 23, p. 254). Está claro, entonces, que para el florentino la autoridad, como poder que gobierna, incluye la demostración de la lucha y el riesgo para ser reconocida por los que la reciben; a la vez, este reconocimiento significa la renuncia de los dominados a la posibilidad de reaccionar contra el poder que gobierna, porque reconocen que esa autoridad puede inteligentemente prever por ellos y estos dedicarse a sus necesidades. En otras palabras, no existe autoridad si no es reconocida. El caso contrario no significa ni más ni menos que la destrucción misma de la autoridad (Kòjeve, 2006, pp.39-45).

La proposición también plantea que el gobierno se ocupa de organizar bienes y riquezas que son puestas en práctica, y asegurar su seguimiento por un conjunto de ministros asociados a específicas funciones de gobierno: protección de la comunidad política frente al exterior, pervivencia de la misma autoridad y mantenimiento de esa misma unidad hacia el interior. Para Maquiavelo, la duración o no de la autoridad en el gobierno depende del exitoso cumplimiento de estas funciones y, para lograrlo, es indispensable elegir adecuadamente a los "secretarios". Los criterios de competencia y fidelidad son los indicadores que permiten conocer cuan sabio y prudente es el gobernante y cuan seguro el cumplimiento de sus decisiones. Maquiavelo no duda en afirmar que "el primer juicio que nos formamos sobre la inteligencia de un señor se basa en los hombres que le rodean" (EI príncipe, cap. XXII, p. 164). Son estos secretarios los que rutinariamente -podemos decir- controlan y administran las instituciones del dominio político y los que, al poner en práctica las decisiones del gobernante, estabilizan su poder y aseguran su dominio. En consecuencia, el tipo de legitimidad de estos secretarios es de orden funcional porque el ejercicio de autoridad proviene de la decisión del gobernante. Maquiavelo le dice al príncipe que nunca será un buen ministro y nunca podrá fiarse de él cuando observe que en todas sus acciones persigue su propio provecho; "porque quien tiene en sus manos el gobierno de otro no debe pensar jamás en sí mismo sino en el príncipe, ni recordarle jamás cosa alguna que no sea de su propio interés" (El príncipe, Cap. XXII, p. 165).

El reconocer las capacidades y conservar la lealtad son condiciones también necesarias porque las acciones autoritativas están cruzadas por el riesgo y el temor. El primero, por la siempre presente posibilidad o proximidad de daños que causen desenlaces irremediables, y el temor porque involucra sentimientos de inquietud y miedo ante ese 
posible e irreparable daño. Para comprender el enorme valor de la relación entre riesgo y temor es indispensable ubicarlos dentro del planteo del autor y, en este sentido, no duda en afirmar que:

un príncipe ha de abrigar dos temores: uno interior, de sus súbitos; otro exterior, de los poderosos príncipes extranjeros. De este último temor se defiende con buenos ejércitos y buenos amigos [...] Y en cuanto a los súbditos, mientras las cosas en el exterior no se muevan, sólo hay que temer que no se conjuren secretamente; por ello, que un príncipe prudente si quiere evitar las consecuencias que la combinación entre riesgo y temor producen, debe escapar de los aduladores y elegir hombres sabios que le digan la verdad sobre las cosas que él pregunta y "nada más". (El príncipe, cap. XIII, p.166)

Pero los secretarios elegidos por la autoridad no sólo ponen en práctica las decisiones del gobierno, sino que funcionan como fusibles, es decir como una especie de productores de cortocircuitos que por delegación del príncipe asumen, aun sin expreso conocimiento, sus acciones como productos de sus propias decisiones. En caso de necesidad política y ante la posibilidad de poner en riesgo la continuidad del gobierno, el uso de la violencia y la crueldad debe ser realizada por estos funcionarios; única forma de proteger al gobernante y al gobierno de la pérdida de apoyos que este tipo de acciones ocasionan en los gobernados. El ejemplo de hacer que otros ejerzan las crueldades por delegación de quien gobierna y luego ante el éxito o fracaso de la acción deshacerse de quienes las ejecutaron queda sucintamente graficado en la figura de Ramiro de Orco, designado por Alejandro VI para gobernar la Romania (EI príncipe, cap.VII, pp. 93-101). Este fue un funcionario despiadado pero eficiente al que César Borgia le concedió plenos poderes para pacificar y unificar la Romagna. Pero, viendo como crecía su poder y buscando borrar el imaginario social producido por sus crueldades, decidió dar a través de su asesinato y la exhibición de su cuerpo en la plaza pública un escarmiento que solucionara simultáneamente ambos problemas (El príncipe, cap. VII, p. 98). De este modo, la eliminación de un funcionario importante respondió no sólo a esta necesidad de apaciguar y amedrentar a la población, sino a la de crear una figura de inocencia del gobernante respecto de los crímenes cometidos por su ministro. En conclusión, la astucia del zorro prevalece en el gobernante sobre la fuerza del león, cuya aplicación y uso había sido previamente autorizada.

\section{Conclusiones}

Al llegar a este punto, resulta conveniente recapitular algunos de los aspectos decisivos planteados en el desarrollo de este trabajo. En primer lugar y, en torno a las interpretaciones que con posterioridad surgieron de la obra de Maquiavelo y, fundamentalmente de El Príncipe, podemos afirmar que el conflicto en torno a las interpretaciones sigue abierto. En los tiempos comprendidos en los siglos XVII y XX y, en lo que va del actual siglo, los 
estudiosos presentaron la obra del florentino en variedades tan amplias que van desde la calificación de la misma como una especie de manual de consejos para los tiranos, o para asesorar al diablo, hasta una valoración más cercana a la mistificación de su persona. Sin embargo, lo que sí podemos destacar es que, a pesar de esta contradictoria proliferación de interpretaciones, se articuló progresivamente un consenso casi general acerca de la importancia de sus escritos para el surgimiento de una nueva ciencia: la ciencia política, que, apoyándose en la evidencia de los hechos, infiere conocimientos técnicos de las leyes y acciones políticas. Además, no hay que dejar de considerar que la introducción de la historia como disciplina ayudó a esta aceptación, al entender que la vida política y social de los dominios políticos-comunidades también está sujeta a estudio.

En segundo lugar, la producción de Maquiavelo y, en especial El Príncipe puede verse como un epitafio del mundo medieval; un acta de defunción de una cosmovisión centrada en una visión teocrática y jerárquica del mundo donde el principio absoluto, el primer principio de todas las cosas, es Dios. Es Dios quién constituye el mundo superior, y en el mundo terrenal, al Imperio; que por esto mismo está en relación de dependencia con respecto al primero. En el mundo secular es, sin embargo, el poder más alto, que luego delega en príncipes, nobles y vasallos. Este mundo jerárquico que predominó durante la Edad Media es al que Maquiavelo con sus escritos y lo que de ellos se desprende, ayudó a poner fin. El origen divino de los reyes le parece una parodia, por no decir un absurdo. Pensar en nuevos principados, o en principados mixtos o hereditarios, o en las repúblicas, no podía hacerse sobre su procedencia divina sino sobre la verdad efectiva de las cosas, sobre lo que es y no lo que debe ser. De ahí que, como ya hemos dicho, trastoque el objetivo ético-normativo por el de utilidad y necesidad (dándole paradojalmente, una dimensión normativa), y cuestione a la religión cristiana porque reemplaza la gloria de la grandeza del hombre político por el reino de los desposeídos y humildes. La acción política no se realiza en un paraíso terrenal porque sí hay una certeza, es la certeza de la inexistencia de la inmutabilidad, de la paz permanente y de que la moral cristiana es incompatible con la ampliación y conservación del poder de la autoridad en y de los dominios políticos concretos.

En tercer lugar y, en cuanto a las tesis se refiere, podemos dar una conclusión provisional. Por su misma condición proposicional, requieren de explicaciones fundamentadas más extensas y de una búsqueda de fuentes documentales más profunda. Sin embargo, las mismas se realizan sobre las apreciaciones que el mismo Maquiavelo realiza sobre los hombres dotados de grandeza que fundaron, gobernaron o reformaron dominios políticos territoriales. Seguimos su propia indicación al considerar que leyendo lo sucedido en el pasado, se puede entender el presente. Así como Maquiavelo estudiaba a los grandes hombres de acción del pasado para poder ayudar a actuar, nosotros intentamos estudiar a Maquiavelo para poder aprender a pensar nuestra realidad.

Con respecto a la primera tesis, referida a que el gobierno es la expresión más significativa de la forma de dominación, de la realidad de la fuerza y de una visión vertical de la política, podemos concluir sosteniendo que es la elección de los fines y el cumplimiento de los objetivos de gobierno lo que ubica al gobierno en el centro del universo 
político. Por medio de sus análisis Maquiavelo da coherencia a actividades del gobierno según el punto de vista del interés, donde la ocasión se constituye en el parámetro que ubica la acción del gobernante. Sus respuestas a las preguntas sobre el quién y el cómo del arte de gobernar se las formula desde la perspectiva condicionada por el punto de vista del análisis político como ámbito independiente respecto de las visiones predominantes acerca del sentido ético normativo sobre el buen gobierno ${ }^{13}$. El fenómeno gobierno; en definitiva, se valora por sus resultados positivos con respecto a la continuidad del dominio, la seguridad de sus habitantes y la pervivencia del gobernante y su gobierno. En este contexto, la acción de gobernar posee una condición temporal y existencial, ya que impone elecciones irreversibles.

A partir de esta proposición, la segunda tesis hace hincapié en la idea de éxito como criterio de distinción entre el buen y el mal gobierno. Los indicadores de efectividad y eficacia son las dimensiones fundantes del gobierno porque apuntan específicamente a entender esta diferenciación. Se puede sostener que para Maquiavelo un gobernante es prudente, sabio, prudentísimo cuando el gobernante puede llevar adelante acciones buenas, pero sin olvidarse de aplicar aquellas ponderadas como malas cuando la ocasión así lo requiere. El gobierno efectivo y eficaz es aquel en el que el gobernante sabe ser "medio hombre y media bestia". Estas categorías ilustran la naturaleza de la elite que gobierna e indican los extremos de una progresión de tipos de autoridad.

El cometido de la tesis tres da un plus de significación a los planteos precedentes y presenta algunas ideas sobre el concepto de autoridad como poder que gobierna y sobre la necesidad de existencia de funcionarios secretarios-, para poner rutinariamente en práctica las políticas del gobierno, contribuir a materializar sus funciones prioritarias y, a la vez, ser capaces de aceptar riesgos y costos que neutralicen las oposiciones y, en consecuencia, eviten al gobierno situaciones de anarquía por la pérdida de apoyos y renuncia al seguimiento de los gobernantes por parte de los gobernados. En consecuencia, le corresponde al gobernante distribuir la autoridad entre sus secretarios que ejercen una autoridad trasmitida y dependiente porque está en función de la del Jefe. Es esta relación la que pone de manifiesto la autoridad autónoma del gobernante para la distribución de los cargos que, acotación al margen, siempre se realiza "entre amigos". De esta manera, el gobierno siempre está conducido por pocos y, en correspondencia con la proposición anterior, "no existen tiranos ni héroes" sino tan sólo gobernantes con más o menos autoridad en el cumplimiento de sus fines.

- Para cerrar estas conclusiones, podemos decir que Maquiavelo nunca fue maquiavélico, si por maquiavelismo se entiende, a nivel personal, el reino de la hipocresía, de la sagacidad, de la astucia, del engaño y de la fuerza a cualquier precio. Su teoría política no es la expresión

\footnotetext{
${ }^{13}$ La concepción normativa del buen gobierno y su diferenciación del mal gobierno se realizaba, en principio, sobre la base de dos normas insustituibles: la de cumplimento o no de las leyes y la de la opción entre el bien común y bien individual del gobernante. El famoso fresco de Ambrogio Lorenzetti "del Buon governo" (1338-340) realizado para decorar el Palazzo Pubblico de Siena es una clara representación de lo expuesto.
} 
psicológica de su persona y no descarta el empleo de estas universales herramientas. Maquiavelo como hombre del Renacimiento no inclinaba su aceptación hacia visiones relativas (propias de nuestros tiempos) sino que buscaba principios universales, aplicables a todo dominio político, más allá de su denominación y organización y a todo gobierno que reclame para sí la condición de eficacia y efectividad. La historia le permitía encontrar esos principios universales, ya que cualquiera que advierta el pasado puede percibir el imperio en todos los ordenamientos de las mismas pasiones y los mismos deseos. Y, sin embargo, no nos olvidamos tampoco que, en tanto teoría política, las obras de Maquiavelo supieron tomarle el pulso a las situaciones de su tiempo, valorando y proponiendo comportamientos de acuerdo a la dinámica inherente a ella.

\section{Referencias Bibliográficas}

BOCK, Gisela. (1993). Civil discord in Machiavelli's Istorie Fiorentine, en Bock, G., Skinner. Q. Machiavelli and the Republicanism (Vol. 18). Cambridge: Cambridge U. Press.

BORÓN Atilio. (2000). Maquiavelo y el infierno de los filósofos. En Varnagy Tomás. Fortuna y virtud de la república democrática. Ensayos sobre Maquiavelo. Buenos Aires: CLACSO.

http://www.bibliotecavirtual.clacso.org/ar/libros/Maquiavelo/boron.pdf

COLISH, Marcia L. Republicanism, religion and Machiavelli's Savonarola moment. Journal of History of Ideas, vol. 60, (4), 597-616.

DEL ÁGUILA TEJERINA, Rafael. (1990). Maquiavelo y la teoría política renacentista. En Fernando Vallespín (Compilador). Historia de la teoría política. Madrid: Alianza Editorial.

DOMÉNECH, H.P. (1988). Maquiavelo en España: presencia de sus obras en los siglos XVI y XVII. Fundación Universitaria Española.

---. (1992). Vida y obra de Maquiavelo. En Maquiavelo Nicolás El Príncipe, La Mandrágora. Madrid: Ediciones Cátedra, pp.9-68.

EYMAR, M., \& STRAUSS, L. (2010). La persecución y el arte de escribir. Buenos Aires: Amorrortu.

FUNES, E., \& Hilb, C. (2004). La desunión: república y no-dominación en Maquiavelo. Buenos Aires: Gorla.

FUNES, Ernesto. (2014). Maquiavelo: el cartógrafo de la modernidad. En Smola Julia y Gabriel Vommaro (comp.). Variaciones sobre Maquiavelo. A 500 años de El príncipe. Buenos Aires: Universidad Nacional de General Sarmiento.

GUICCIARDINI, Francesco. (1971). Storia d'Italia, Libro 18, cap. 8. Torino: Einaudi, p.847.

HILB, Claudia. (2000). Maquiavelo, la república y la "virtù". Várnagy, Tomás. Fortuna y virtud en la República democrática: ensayos sobre Maquiavelo. Buenos Aires: Gráficas y Servicios. Pp. 127-147.

MACHIAVELLI Niccolò. (2000). Discorsi sopra a prima deca di Tito Livio seguiti dalle Considerzioni intorno ai Discorsi del Machiavelli di Francesco Guicciaddini. Corrado Vivanti [Introduzione]. Torino: Einaudi. 
MAQUIAVELO Nicolás. (1992). El Príncipe, La Mandrágora. Edición y Traducción de Helena Puigdoménech. Madrid: Ediciones Cátedra.

---. (1996). El Príncipe. Edición y Traducción de Lelio Fernández. Barcelona: Buenos Aires: Editorial Norma.

---. (1987). Discursos sobre la per década de Tito Livio. Edición y traducción de Ana María Arancón. Madrid: Alianza Editorial.

---. (2009). Historia de Florencia. Traducción de Félix Fernández Murga, estudio de contextualización Félix Gilbert. Madrid: Tecnos.

---. (2010). Textos Literarios. Traducción, notas e introducción de Nora Hebe Sforza. Buenos Aires: Colihue, pp. 319:32.

MERCEDES, K., \& ANABEL, F.P. (2008). Permanencias y cambios en el Dominio Político. Kerz, Mercedes (compiladora). KÒJEVE Alexandre. (2006). La noción de autoridad. Traducción de Herber Cardoso. Buenos Aires: Nueva Visión.

LINZ, Juan José. (1991). La quiebra de las democracias. Buenos Aires: Alianza Editorial.

MANSFIELD, Harves. (1996). Macchiavelli's Virtue. Chicago -London: University of Chicago Press, pp.13-22.

MORLINO, Leonardo. (1985). Cómo cambian los Regímenes políticos. Madrid: Centro de Estudios Constitucionales.

RINESI Eduardo (2005). Política y tragedia: Hamlet, entre Maquiavelo y Hobbes. Buenos Aires: Colihue.

---. (2014). Efectualidad, pasiones, virtú. En Smola Julia y Gabriel VOMMARO (comp.). Variaciones sobre Maquiavelo. A 500 años de El príncipe. Buenos Aires: Universidad Nacional de General Sarmiento, pp. 49-54.

RUBINSTEIN N. (1987). The History of the Word politics in Early Modern Europe. The Languages of Political Theory in Early Modern Europe, pp. 41-56.

SASSO, Gennaro. (1980). Niccolò Machiavelli, storia del uso pensiero politico. Bologna: Collezione di testi e di studi. Storiografia.

SARTORI. G. (1987). La política, lógica y método en las Ciencias Sociales. México: FCE.

SCHETTINO, H. (2002). Política e imperium en Maquiavelo y Spinoza. Dianoia, 47, 37-66.

SKINNER, Q.D. (1986). Los fundamentos del pensamiento político moderno (No 320 S45 y).

---. (1991) Maquiavelo. Madrid: Alianza Editorial.

STRAUSS, L., \& DE GAMBRA. (1964). Meditación sobre Maquiavelo. Instituto de Estudios Políticos.

VIROLI, M. (1992). From politics to Reason of state: The acquisition and transformation of the language of politics 1250-1600 (Vol.22). Cambridge: Cambridge University Press. 